\title{
Lime Mortars Modified by Complex Silica Sol Additives
}

\author{
S.A. Montaev, V.I. Loganina, N.B. Adilova*, B.T. Shakeshev \\ Zhangir Khan West Kazakhstan Agro-Technical University, \\ 51, Zhangir Khan St., Uralsk, West Kazakhstan, 090009, Kazakhstan \\ * Corresponding author: Tel.: + 7 (7112) 5161 33.E-mail: adnur@mail.ru
}

\begin{abstract}
The paper describes lime mortars used for restoration of monuments and historic buildings, as well as for finishing of newly constructed facilities. To improve the quality of lime mortars we recommend using nanostructured additives (silica sol and its modifications, hydrated sodium silicates, organic mineral additives). We propose the technology of producing modifiers, with the use of local materials. The maturing time of mortars modified by additives has been calculated. The compatibility of modified mortars and previously lime-washed surfaces has been examined. The types of limewash pigments in a wide range of shades have been selected. To enlarge the range of shades we recommend using local materials, such as sand clay of the Nizhny Ablyazovsk deposit (Kuznetsky district, Penza region, Russia).
\end{abstract}

\section{Keywords}

Aging time; complex additives; silica clay; stabilization.

(c) S.A. Montaev, V.I. Loganina, N.B. Adilova, B.T. Shakeshev, 2016

\section{Introduction}

Currently, the market of mortars is one of the fastest growing segments of the building materials industry. Lime mortars are often used for exterior finish of buildings as they ensure an optimal microclimate of buildings and structures owing to high water vapor permeability of coatings. However, lack of waterresistance and durability of mortar coatings hinder the wider use of lime mortars in the exterior finish. Recently, modified mortars possessing high strength, density, crack- and cold resistance, etc. have been used.

Lime mortars are increasingly used for monument restoration, redevelopment and renovation of buildings [1]. The quality and workability properties of mortars can be improved by using mineral additives, such as silica, alum shale, fossil meal, silica clay, diatomaceous earth, tuffs, pumice, fuel ash and slag, etc. The main criterion for the selection of mineral additives used in lime mortars is its hydraulic activity, the ability to influence early strength gains, and reduce shrinkage deformations due to water retention [2].

The use of mineral additives as hydraulically active components leads to improved efficiency of binders, partial substitution of import modifiers, reduced costs of ready mixed mortars and improved workability of finishing mortars. At the same time, the majority of additives can improve only some of the properties and cause degradation of other properties, or remain them unchanged.

To eliminate negative side effects it is necessary to use complex additives consisting of several components (e.g. a combination of superplasticizer and silica fume). However, the existing technological solutions do not ensure the required water-resistance of lime mortars; thus the demand for technical solutions that enhance water-resistance of lime coatings is quite urgent. It is well known that conversion of materials into nanoscale can significantly alter their properties, therefore, one solution to this problem is modification of mortars by nanoparticle additives.

\section{Materials and Methods}

\subsection{Technology for preparation of silica sol as an additive to lime mortars}

A promising method for preparation of silica sol is ion exchange chromatography [3], which is based on reversible exchange between the ions of the sample solution and the ions of the solid support (the ion exchanger). The studies were conducted under column conditions. The ion exchange column (Fig. 1) filled with KU-2 cation exchanger was used for silica sol preparation. 
Prior to filling the column the cation exchanger was treated as follows: it was placed in a beaker and flooded with $5 \%$ sodium hydroxide solution. After 3 hours the alkaline solution was poured off, and the cation exchanger was thoroughly washed with water to remove low molecular weight fractions. Then a $10 \%$ hydrochloric acid solution was poured, and the cation exchanger was left to swell for a day. A wad of glass wool 2 was placed at the bottom of the column to retain a cation exchanger layer and allow for free flow of the solution. The cation exchanger 3 was placed on a wad of glass wool, and then it was covered with glass wool and glass beads on the top to prevent it from bulking when pouring the solution. The liquid level in the column did not fall below the upper limit of the cation exchanger.

The prepared column with cation exchanger in Hform was washed with distilled water till acid reaction disappeared. A solution of sodium silicate of a certain concentration was prepared from liquid glass with a density of $1.48 \mathrm{~g} / \mathrm{cm}^{3}$. After the solution of sodium silicate was placed on the top of the column, the valve was opened to reach the desired fluid flow rate through the ion exchanger.

The ion-exchange reaction on the cation exchanger can be represented as follows:

$$
2 \mathrm{HR}+\mathrm{Na}_{2} \mathrm{SiO}_{3}=2 \mathrm{NaR}+\mathrm{SiO}_{2} \cdot n \mathrm{H}_{2} \mathrm{O} .
$$

As was established in the course of experiments, the optimal concentration of sodium silicate solution was $6.2-6.6 \%$. Exceeding this concentration of sodium silicate solution resulted in the formation of unstable silica sol and sol-to-gel transition in the ionexchange column. The reduction in the concentration of sodium silicate solution resulted in the formation of low concentration sol.

Silica sol with pH $4.5-5$ density of $1013 \mathrm{~kg} / \mathrm{m}^{3}$ was used as an additive to lime mortars. The results describing silica sol stability were in agreement with literature data [4-6].

Polysilicic acids are practically insoluble in water, and they can easily form colloidal solutions - sols. The stability of silica sols is strongly dependent on the solution $\mathrm{pH}$. Relatively quickly, they can be transformed into gel at a $\mathrm{pH}$ of 5-6 and that of less than 1 . In the $\mathrm{pH}$ range of 2-4 the resistance of silica sols increased.

We studied the effect of sodium silicate modulus on the density of the silica sol. It was found that with the increased sodium silicate modulus, the concentration and the density of the silica sol increased. Thus, when the sodium silicate modulus was 2.8 , the density reached $1013 \mathrm{~kg} / \mathrm{m}^{3}$, when the sodium silicate modulus was 2.9 , the density was $1019 \mathrm{~kg} / \mathrm{m}^{3}$. Further studies showed that for the optimal stability the density of the

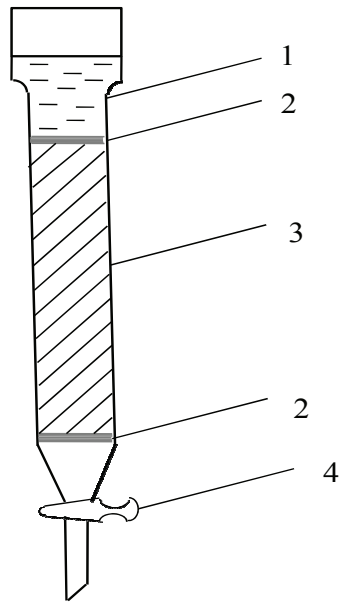

Fig. 1. Ion exchange column:

1 - sodium silicate solution; 2 - glass wool; 3 - cation-exchange resin; 4 - valve

sol should correspond to the value of $1013 \mathrm{~kg} / \mathrm{m}^{3}$. Thus, we obtained $4 \%$ silica sol, and diluted it to a $2 \%$ sol, which was used for the production of lime finishing mortars.

\subsection{Determination of the particle size of silica sol}

Determination of the particle size of silica sol was carried out by turbidimetry $[7,8]$. Turbidimetry is based on measuring the intensity of the light passing through the dispersion system. To determine the particle size of the sol we used the Rayleigh and Geller equations [9].

D. Rayleigh studied the scattering of light in a dispersed system, satisfying the following conditions:

1) The scattering particles are small, and their shape is close to isometric; the largest particle size is more than 30 times smaller than the wavelength of incident light;

2) The particles are not colored, they do not conduct electric current and they are optically isotropic;

3) The concentration of particles is small; the distance between them is considerably greater than the wavelength of incident light;

4) The volume of a disperse system through which the scattered light passes is small, and it cannot take into account the secondary light scattering.

The scattered light can be considered as fictitious absorption; so we can assume that the laws of light scattering satisfy the Beer - Bouguer - Lambert law:

$$
\ln I_{0} / I_{\mathrm{p}}=2.3 D=\tau l,
$$

where $I_{0}$ is the intensity of the light passing through the system; $D=\lg I_{0} / I_{\mathrm{p}}$ is absorbance; $I_{\mathrm{p}}$ is the intensity of the polarized scattered light; $\tau$ is the turbidity of the system; $l$ is the thickness of the system layer. 
The turbidity $\tau=I_{\mathrm{p}} / I_{0}$, and the absorbance $D$ are proportional to the concentration and the square of the particle volume. This makes it possible to determine the particle size and concentration by the absorbance of the system, using a method of comparison with conventional systems with the help of photoelectric colorimeter.

Rayleigh's equation is applicable to determining the size of spherical particles if their radius $r$ is not more than $1 / 20$ of the wavelength $\lambda$ of the incident light, then the radius of the particle is equal to:

$$
r=\left(\frac{3 \tau \lambda^{4}}{4 \pi c F}\right)^{1 / 3},
$$

where $\lambda$ is the wavelength of incident light, nm; $F$ is the function of refractive indices; $c$ is the volume concentration, $\mathrm{cm}^{3} / \mathrm{cm}^{3}$.

If the size (diameter) of the particles is $1 / 10$ to $1 / 3$ of the light wavelength and refractive indices of the medium and the particles do not differ much, for the description of the light scattering in the system one can use the following empirical equation proposed by W. Geller:

$$
D=k \lambda^{-n} \text { и } D=k^{\prime} \lambda^{-n},
$$

where $k$ and $k^{\prime}$ are constants that are independent of the wavelength.

The dependencies $\lg D$ (or $\lg \tau$ ) from $\lg \lambda$ in accordance with Eq. (3) represent a straight line, the slope of which is equal to the $n$-minus exponent. The value of the exponent $n$ in these equations depends on the ratio between the particle size and the wavelength of the incident light, characterized by a parameter $Z$ :

$$
Z=8 \pi r / \lambda \text {. }
$$

If $Z$ increases, the value $n$ decreases, approaching the limit of 2 for particles having a radius greater than the wavelength. For small values of $Z$ Rayleigh's equation is satisfied and $n=4$. To determine the size of the sol particles using Geller's equation the exponent $n$ in Eq. (3) was determined on the basis of turbidimetric data. For this experiment, the absorbance of the system at different wavelengths (in a fairly narrow range of $\lambda$ ) was measured and a graph was plotted in the $\lg D-\lg \lambda$ coordinates. The exponent $n$ was determined by the slope ratio of the resulting line. The value of $Z$ was determined by the value $n$, and then the formula (4) was used to calculate the average radius of the particles of the considered disperse system.
It should be noted that this method and Rayleigh's equation are applicable only to "white" sols, i.e. unpainted dispersed systems (the method is based only on light scattering).

The values of the particle size of silica sol were determined by the maturing period. Sol absorbance was measured at different maturing periods with different volume concentration $c$, using precision cells of $3 \mathrm{~cm}$ in length and a filter No. $9\left(\lambda_{\mathrm{vac}}=625 \mathrm{~nm}\right)$. Using the formula (1) we calculated turbidity $\tau$. The graphs were plotted in the $\tau / c-c$ coordinates (Fig. 2). By extrapolating the graphs we found the value of $\tau / c$ when $c=0$. The value of $\tau / c$ obtained when $c=0$ was used to calculate the radius $r$ of the sol particles using Rayleigh's equation (2).

When calculating the function $F$ in Rayleigh's equation (2) it was assumed that the refractive index of the dispersion medium (water) $n_{0}=1.333$, and that of the sol particles $n_{1}=1.55$. The wavelength in the medium was determined as $\lambda=\lambda_{\text {vac }} / n_{0}$, where $\lambda_{\text {vac }}$ is the wavelength of the incident light in vacuum, $\mathrm{nm}$.

$$
F=24 \pi^{3}\left(\frac{n_{1}^{2}-n_{0}^{2}}{n_{1}^{2}+2 n_{0}^{2}}\right)^{2} .
$$

We found the value of $F$ to calculate the radius of the sol particle:

$$
F=24 \cdot 3.14^{3} \cdot\left(\frac{1.55^{2}-1.333^{2}}{1.55^{2}+2 \cdot 1.333^{2}}\right)^{2}=8.197 .
$$

Geller's equation (3) was used to determine the particle size of silica sol at a late stage of maturing, beginning from $6^{\text {th }}$ day.

\section{Ratio of turbidity to the volume concentration of sol $\tau / c$,} $\mathrm{cm}^{2} / \mathrm{cm}^{3}$

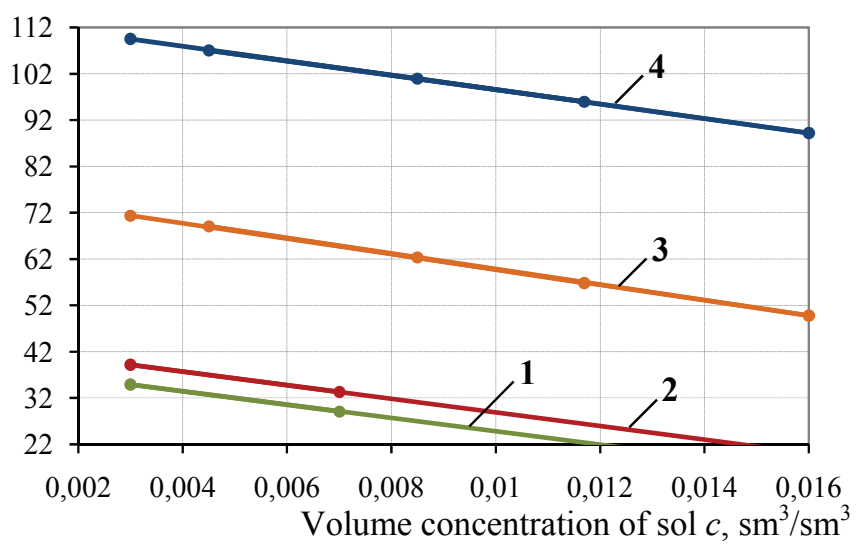

Fig. 2. Dependence $\tau / \mathrm{c}-\mathrm{c}$ under the period of aging of silica sol:

$1-1$ day; $2-3$ days; $3-4$ days; $4-5$ days 
Table 1

\section{The dependence of the particle radius} on the maturing period of silica sol

\begin{tabular}{cc}
\hline $\begin{array}{c}\text { Maturing period of silica sol, } \\
\text { days }\end{array}$ & $\begin{array}{c}\text { Sol particle radius, } \\
\mathrm{nm}\end{array}$ \\
\hline 1 & 17 \\
3 & 18 \\
4 & 22 \\
5 & 25 \\
7 & 57 \\
12 & 83 \\
15 & 113 \\
19 & 140 \\
\hline
\end{tabular}

Table 1 shows the values of the radius of sol particles depending on the period of aging.

The experimental data showed that if the maturing period was 15 days or more, the sol particles got bigger, the turbidity of sol was visually observed, which led to a decrease in the sol activity.

\subsection{Stabilization of silica sol}

Stabilization of silica sol was evaluated in terms of the surface potential and the value of the thickness of the diffuse ion layer.

Free silicic acid exisits in several forms: $\mathrm{H}_{4} \mathrm{SiO}_{4}$ or $2 \mathrm{H}_{2} \mathrm{O} \cdot \mathrm{SiO}_{2}$ - orthosilicic acid, $\mathrm{H}_{2} \mathrm{SiO}_{3}$ or $\mathrm{H}_{2} \mathrm{O} \cdot \mathrm{SiO}_{2}-$ metasilicic acid, $\mathrm{H}_{2} \mathrm{Si}_{2} \mathrm{O}_{5}$ or $\mathrm{H}_{2} \mathrm{O} \cdot 2 \mathrm{SiO}_{2}$ - two-metasilicic acid (disilicic).

Monomolecular silicic acids are unstable and typically condensed into polymeric, substantially water-insoluble form. In a simplified form, the reaction of their condensation can be represented by the equation:

$$
2 \mathrm{H}_{4} \mathrm{SiO}_{4}=\mathrm{H}_{2} \mathrm{O}+\mathrm{H}_{6} \mathrm{Si}_{2} \mathrm{O}_{7} \text {. }
$$

Further polymerization resulted in the formation of polysilicic acids that were different in composition and structure, but had the general formula $x \mathrm{SiO}_{2} \times y \mathrm{H}_{2} \mathrm{O}$, where $x>1$. The development of siloxane bonds and dehydration of particles increasingly brought them closer to the composition of the colloidal aggregate $\left(\mathrm{SiO}_{2}\right)_{n}$. The latter consisted of tetrahedrons $\left[\mathrm{SiO}_{2}\right]^{4-}$. On the surface it was hydrated by the addition of cations $\mathrm{H}^{+}$to the unsaturated oxygen in the ion $\mathrm{Si}^{-} \mathrm{O}^{-}$ to form $\mathrm{OH}$.

Silica sol was stable up to 15 days. The electrokinetic potential was $0.03-0.103 \mathrm{~V}$. Later, we observed a decrease in electro-kinetic potential.
The formation of disperse systems is accompanied by an increase in the free energy of the system. Consequently, dispersion is thermodynamically unstable, i.e. sooner or later it will collapse spontaneously. Therefore, we can speak only about the relative thermodynamic stability of disperse systems. Relative stability is the ability of the system to maintain unchanged its structure for some time, i.e., particle sizes and their uniform distribution in the volume of the system [10].

To prevent aggregation of particles and protect hydrosols from coagulating action of electrolytes we used macromolecular compounds and colloidal surfactants soluble in water. Their stabilizing effect is based on the formation of the dispersed phase of adsorption of gelled films on the surface; their formation is caused by a decrease in the interfacial tension, as well as structural and mechanical properties of the surface layers.

When conducting the studies, we investigated the stabilization of silica sol using the following polymeric additives (gelatin, polyvinyl alcohol PVA and cation acrylamide K-280). The threshold of rapid coagulation was found by turbidimetric method for the electrolyte $\mathrm{V}_{\mathrm{k}}$ at which the absorbance of sol reached a maximum value. The threshold value of coagulation $c_{k}$ was calculated by the formula

$$
c_{\mathrm{k}}=\frac{c_{\mathrm{el}} V_{\mathrm{k}}}{V},
$$

where $c_{\mathrm{el}}$ is the applied electrolyte concentration, mol/l; $V$ is sol volume, $\mathrm{ml} ; V_{\mathrm{k}}$ is electrolyte volume, $\mathrm{ml}$.

The aluminum sulfate solution was used as a coagulating electrolyte for silica sol. The choice of this type of electrolyte was explained by the following reasons. Lime mortars are characterized by shrinkswell behavior that predetermines their low crack resistance. To reduce the strain it was proposed to add aluminum sulfate as an expanding agent. The electrolyte was administered in the form of a $5 \%$ concentration. Sol, water and electrolyte in the amount of $5 \mathrm{ml}$ of each were poured into the test tube, changing the ratio of water and electrolyte so that the total amount of samples remained the same. The electrolyte was introduced into each sample of sol 2-4 minutes before measuring its absorbance. The absorbance of sol was measured in each sample by using a photoelectric colorimeter and color filter No. 9. The dependence graph $D=f\left(V_{\mathrm{el}}\right)$ for $\mathrm{Al}_{2}\left(\mathrm{SO}_{4}\right)_{3}$ was plotted; using the graph the threshold volume of electrolyte $V_{\mathrm{k}}$ causing rapid coagulation of sol was found; using the formula (6) the value of $c_{\mathrm{k}}$ was calculated. 
The experiment proved that gelatin, polyvinyl alcohol (PVA) and cation acrylamide K-280 were effective stabilizers for the silica sol.

The protective ability of the stabilizer solution relative to the selected sol is characterized by the protective number $\mathrm{S}$, which is the amount of substance required to stabilize the volume unit of sol. The concentration of the gelatin solution was $5 \%$, that of PVA was $2 \%$, and that of cation acrylamide copolymer K-280 was $8 \%$. Using Geller's equation the particle size of the stabilized silica sol was calculated for the one-day maturing period: gelati + sol, $\quad r=64 \mathrm{~nm} ; \quad$ sol + PVA, $\quad r=52 \mathrm{~nm}$; $\mathrm{sol}+$ cation acrylamide $\mathrm{K}-280, r=78 \mathrm{~nm}$.

\subsection{The structure of lime mortars modified by sol additives}

The work on finishing lime mortars was carried out in two directions: the creation of decorative plaster and paint formulations.

When developing the formulation of decorative plaster, we considered the recommendations of national and international regulations, including the provisions of "Code of practice for design and construction".

To expand the range of shades of lime mortars we used sand clay from the Nizhny Ablyazovsk deposit (Kuznetsky district, Penza region, Russia). According to the RF Committee for Geology and Mining, the reserves of clay sand Cat. A + B make up 82 thousand tons, with the power utility thickness of 1-7 m, the average length of $120-140 \mathrm{~m}$, the width of 70-90 m.

The filler is clay sand of red-brown color, with an average particle diameter of $17.2 \cdot 10^{-6} \mathrm{~m}$, the specific surface $S_{\mathrm{sp}}=132 \mathrm{~m}^{2} / \mathrm{kg}$; the chemical composition of sand is as follows, \%: $\mathrm{SiO}_{2}$ is 89.34-95.48; $\mathrm{Al}_{2} \mathrm{O}_{3}$ is 2.45-5.06; $\mathrm{Fe}_{2} \mathrm{O}_{3}$ is $0.31-4.7$; the pigment content in the sand is $97 \mathrm{~kg} / \mathrm{m}^{3}$. The reserves of ocher sands Cat. $\mathrm{A}_{2}$ make up 80 thousand cubic meters, or 106.4 thousand tons. The average density of rocks ranges from 1.271 to $1.379 \mathrm{~g} / \mathrm{cm}^{3}$. The content of soluble salts in the rocks is insignificant and varies from traces to $2.81 \%$. The content of iron oxides in a rich rock is $15.59-21.98 \%$. The amount of rich rock obtained from mineral raw materials by wet enrichment ranges from 1.56 to $16.37 \%$.

In developing the formulation of lime mortars, the ratio of lime to sand (L:S) ranged from 2 to 4 . When developing the formulation of the mastic paint of the test sample, we used milled sand with a specific surface $S_{\mathrm{sp}}=507 \mathrm{~m}^{2} / \mathrm{kg}$; for the formulation of finishing plaster we used the sand fraction of $0.314-0.14 \mathrm{~mm}$. Cube samples were made of limesand mixture, with the ratio of water to lime $\mathrm{W} / \mathrm{L}=2$ and 1.2, respectively. For comparison, we also used sand fraction 0.314-0.14 $\mathrm{mm}$ from the Ukhta deposit. The slaked lime was used as a binder, with the activity of $71-76 \%$, a true density of $2230 \mathrm{~kg} / \mathrm{m}^{3}$ and a bulk density of $280 \mathrm{~kg} / \mathrm{m}^{3}$, and a specific surface area $\left(S_{\mathrm{sp}}\right)$ of $559 \mathrm{~m}^{2} / \mathrm{kg}$.

The analysis of experimental data showed that lime mortars with sand fraction of $0.314-0.14 \mathrm{~mm}$ had low strength component for a 28-day maturing period $R_{\text {com }}=0.51-0.81 \mathrm{MPa}$. For the mixtures with milled sand in the ratio of (lime to filler) $\mathrm{L}: \mathrm{F}=1:(2-4)$ the strength of the samples was $R_{\mathrm{com}}=0.76-0.95 \mathrm{MPa}$.

Given the low strength of mortars we used silica sol as an additive. To study the formation of the structure and properties of coatings and finishing mortars on their basis we examined samples with different ratios of lime to sol (L:SL). The obtained 2 and $4 \%$ silica sols were administered together with water to the mortar mixture, where the ratio of lime to sol was $\mathrm{L}: \mathrm{SL}=1: 0.25,1: 0.5 ; 1: 1$ and $1: 1.5$. The mixtures with the ratio of $\mathrm{L}: \mathrm{S}=1: 3, \mathrm{~W} / \mathrm{L}=2$, for milled sand $S_{\mathrm{sp}}=507 \mathrm{~m}^{2} / \mathrm{kg}$.

It was found that the introduction of a silica sol additive improved the compressive strength of the mortar. Thus, after the introduction of a $2 \%$ silica sol in the ratio $\mathrm{L}: \mathrm{SL}=1: 1$, the compressive strength of the solution for a 28-day maturing period $R_{\text {com }}=1.7 \mathrm{MPa}$, while the compressive strength of the solution without a sol additive was $0.85 \mathrm{MPa}$. The increased concentration of sol resulted in a greater increase in strength. After administering a $4 \%$ sol in the ratio $\mathrm{L}: \mathrm{SL}=1: 1$, the compressive strength $R_{\text {com }}=1.98 \mathrm{MPa}$. A further increase in the content of silica sol in the formulation of lime finishing coatings in the ratios $\mathrm{L}: \mathrm{SL}=1: 1.25$ and $\mathrm{L}: \mathrm{SL}=1: 1.5$ resulted in a slight increase in strength. It was found that for physical and mechanical properties the optimal ratio of lime to sol was $\mathrm{L}: \mathrm{SL}=1: 1$ with the use of a $2 \%$ silica sol. The application of a $2 \%$ silica sol was explained by its viability, although a $4 \%$ sol resulted in a greater increase in strength.

For comparison, we also examined ortars with the additives of Aerosil 150, silica clay and microwollastonite.

The study of the hardening kinetics of lime mortars showed that the sol effectiveness was observed at an early age of maturing. Thus, for the composition in the ratio $\mathrm{L}: \mathrm{F}=1: 3, \mathrm{~W} / \mathrm{L}=2$ with an additive of a $2 \%$ silica sol in the ratio $\mathrm{L}: \mathrm{SL}=1: 0.5$ and a 7 -day maturing period the compressive strength was 
$R_{\text {com }}=0.68 \mathrm{MPa}$, and for a 28 -day maturing period $R_{\text {com }}=1.23 \mathrm{MPa}$, whereas for the control mixture $R_{\text {com }}=0.25 \mathrm{MPa}$ and $R_{\text {com }}=0.85 \mathrm{MPa}$, respectively.

A longer maturing period of the silica sol up to 15 days reduces its activity and causes a minimal increase of $29 \%$ in the compressive strength after 28-day airdry maturing period in the ratio $\mathrm{L}: \mathrm{SL}=1: 1$ compared with that of $100 \%$ for a one-day maturing period of sol. Introduction of the Aerosil 150 additive enhanced the compressive strength only by $11 \%$ compared with the control mixture for a 28-day maturing period. In order to reduce swelling and deformation, and accelerate the maturing period it was proposed to introduce the additive mixture of aluminum sulfate $\mathrm{Al}_{2}\left(\mathrm{SO}_{4}\right)_{3}$ in an amount of coagulation threshold $c_{\mathrm{k}}=0.006 \mathrm{~mol} / \mathrm{l}$, or $4-4.5 \%$ by weight of a $2 \%$ silica sol (or $4-4.5 \%$ by weight of lime).

The experimental data showed that the stabilized sol had less active interaction with lime. After adding the stabilized sol for a 28-day air-dry hardening period the compressive strength was $\mathrm{R}=1.45 \mathrm{MPa}$ and that of unstabilized sol was $1.54 \mathrm{MPa}$. When introducing additives $\mathrm{Al}_{2}\left(\mathrm{SO}_{4}\right)_{3}$ and the stabilized sol in a ratio $\mathrm{L}: \mathrm{SL}=1$ : the strength was $R=1.68 \mathrm{MPa}$, i.e. an increase in strength was $107 \%$ compared to the control sample.

To study solid-phase reactions occurring in the process of structure formation of finishing mortars we applied a high-quality X-ray scattering and a thermodynamic analysis of possible reactions.

\subsection{Changes in the technology and rheological properties of lime mortars modified by silica sol additives}

Rheological properties of mortars were evaluated by the plastic strength parameter, which was measured using a cone-and-plate rheometer KR-3. It was found that plastic strength increased with an increase in limesand ratio.

Thus, after 16 hours of tempering of mortar in the ratio $\mathrm{L}: \mathrm{S}=1: 4$ the plastic strength was $0.0007 \mathrm{MPa}$, and that of the mortar in the ratio $\mathrm{L}: \mathrm{S}=1: 2$ was $0.00005 \mathrm{MPa}$.

After $16 \mathrm{hrs}$ of tempering mortars in the ratio $\mathrm{L}: \mathrm{S}=1: 4$ (sand fraction $0.314-0.14 \mathrm{~mm}$ ) with a silica sol additive had the plastic strength of the mixture equal to $0.0009 \mathrm{MPa}$, while that of the control mixture was $0.0007 \mathrm{MPa}$. When adding a silica sol additive, the plastic strength was accelerated in the mortars using sand fraction $0.314-0.14 \mathrm{~mm}$ and milled clay sand. After $16 \mathrm{hrs}$ of tempering of the mortar in the ratio $\mathrm{L}: \mathrm{F}=1: 3$ (milled clay sand) with and a silica sol additive in the ratio of $\mathrm{L}: \mathrm{SL}=1: 1$, the plastic strength was $0.0010 \mathrm{MPa}$, and that of the control mixture was $0.0002 \mathrm{MPa}$. The plastic strength of the mixture with an Aerosil 150 additive was $\tau=0.0003 \mathrm{MPa}$.

As mentioned above, a longer maturing period of the silica sol (up to 15 days) reduces the activity of its interaction with lime. Thus, after $16 \mathrm{hrs}$ of tempering, the plastic strength of the mixture with an additive of sol (the ratio of $\mathrm{L}: \mathrm{SL}=1: 1$ ) was $0.0006 \mathrm{MPa}$, while the plastic strength of the mortar with an additive of the silica sol (a one-day maturing period) in the ratio of $\mathrm{L}: \mathrm{SL}=1: 1$ was higher and amounted to $0.0010 \mathrm{MPa}$.

The amount of silica sol (the maturing period of 15 days) had little influence on the plastic strength of the mixture. When the ratio of lime to sol $\mathrm{L}: \mathrm{SL}=1: 0.5$, after $16 \mathrm{hrs}$ of tempering the plastic strength of the mixture was $0.00060 \mathrm{MPa}$, while that for the ratio of $\mathrm{L}: \mathrm{SL}=1: 1$ was $0.00063 \mathrm{MPa}$.

The evaluation of the degree of drying was performed on a five-point scale. The control mixture was the mortar in the ratio of lime to sand $\mathrm{L}: \mathrm{S}=1: 4$, the sand fraction with a diameter of $0.314-0.14 \mathrm{~mm}$, $\mathrm{W} / \mathrm{L}=1.2$. The research results showed that lime mortars modified by a $2 \%$ silica sol additive were characterized by a slow drying time. For example, the drying time (level 3 on the scale) of the mixture modified by a $2 \%$ silica sol additive on a concrete substrate was 17 minutes, while that of the control mixture (without additives) was 7 minutes. Modifying the mixture with a $2 \%$ gelatin-stabilized silica sol and $\mathrm{Al}_{2}\left(\mathrm{SO}_{4}\right)_{3}$ additive accelerated the drying time of the coating on the concrete substrate. The dependence of the drying time on the amount of water used for tempering was identified. The drying time (level 3 on the scale) of the mixture with $\mathrm{W} / \mathrm{L}=1.2$ on the concrete substrate was 9 minutes, while that of the control mixture with $\mathrm{W} / \mathrm{L}=2.6$ was 15 minutes.

The experiment showed that the drying time of the mortar is also influenced by the substrate porosity. The mixtures which were administered to the glass substrate took longer to mature. The drying time (level 5 on the scale) on the glass substrate was 30 minutes, and that on the concrete substrate was 17 minutes.

\subsection{Workability of the modified finishing mortars}

The analysis of scientific literature and the results of field surveys suggest that cracks are one of the most common types of defects of finishing mortar coatings [11]. The list of defects includes cracks at the vertical joints, multi-shaded coating, and delamination. However, with maturing of coatings, the priority of defects can change and new types of defects can emerge. 
It should be noted that professionals developing mortars and technologies of their application should direct their efforts at improving crack resistance of mortars as this is the most typical and widespread type of defect [12].

In this regard, we paid considerable attention to the crack resistance of the developed mortars. We found that the varying factors were the ratio of lime to sand $(\mathrm{L}: \mathrm{S})$, complex additives of silica sol, modifying additives, filler composition. Ricem (polyacrylic fibers) was used as a modifying additive, which was introduced in an amount of $0.2 \%$ by weight of lime, together with mixing water.

To evaluate the crack resistance of finishing coatings we used the crack resistance coefficient, which was calculated by the formula:

$$
K_{\mathrm{cr}}=\frac{R_{\mathrm{bend}}}{R_{\mathrm{com}}},
$$

where $R_{\text {bend }}$ is tensile strength in bending, MPa; $R_{\text {com }}$ is compressive strength, MPa.

The experimental data showed that the most crack resistant was the lime-and-sand mixture, with sand fraction of $0.314-0.14 \mathrm{~mm}$, taken in the ratio of $\mathrm{L}: \mathrm{S}=1: 4, \mathrm{~W} / \mathrm{L}=1.2$, modified by a $2 \%$ stabilized silica sol and $\mathrm{Al}_{2}\left(\mathrm{SO}_{4}\right)_{3}$ additives. The coefficient of crack resistance was $K_{\mathrm{cr}}=0.63$. Also, the coefficient of crack resistance increased for the mixture of lime and filler, in the ratio of $\mathrm{L}: \mathrm{F}=1: 3, \mathrm{~W} / \mathrm{L}=2$, milled sand clay $\left(S_{\mathrm{sp}}=507 \mathrm{~m}^{2} / \mathrm{kg}\right)$, modified by a $2 \%$ stabilized silica sol and $\mathrm{Al}_{2}\left(\mathrm{SO}_{4}\right)_{3}$ additives. The coefficient of crack resistance was $K_{\mathrm{cr}}=0.61$. These mixtures had the following values of compression strength $R_{\text {com }}=1.68$ and $R_{\text {com }}=1.87$, tensile strength in bending $R_{\text {bend }}=1.05$ and $R_{\text {bend }}=1.14$, respectively.

\section{Conclusion}

We described lime mortars used for restoration of cultural heritage monuments and historical buildings, as well as finishing of newly erected buildings. The quality of mortars can be improved by using nanomodified additives such as silica sol and its modifications. We proposed a technology of obtaining modifying agents on the basis of local materials. Maturing characteristics of lime mortars were examined. It was established that mortars modified by silica sol additives have improved characteristics.

\section{References}

1. Demyanova, V.S., et al. (1997) Vysokojeffektivnye suhie smesi razlichnogo assortimenta i naznachenija [Highly effective mortars of different range and purpose]. Stroitel'nye materialy i izdelija: Materialy XXIXnauch.-tehn. Konf [Building Materials: Proceedings of the $29^{\text {th }}$ Research Conference]. ch2, 30. (Rus)

2. Pukharenko, Yu.V., et al. (2011) Restavracija istoricheskih ob\#ektov s primeneniem sovremennyh suhih stroitel'nyh smesej [Restoration of historic buildings using advanced mortars]. Vestnik grazhdanskih inzhenerov [Bulletin of Civil Engineers]. (1), 98-103. (Rus)

3. Frolov, Yu.G. (1982) Kurs kolloidnoj himii. Poverhnostnye javlenija i dispersnye sistemy [A course in colloid chemistry. Surface phenomena and disperse systems]. M.: Himija. (Rus)

4. GOST 29234 12-91 (1992) Peski formovochnye. Metod opredelenija formy zeren peska [Sands for molding. The method of determining the shape of sand particles]. M.: Izd-vo standartov. (Rus)

5. Demidenok, K.V. (2011) Material composition and technical properties of bentonite-like clays of the Central region of Russia and the possibility of increasing of their quality for using in the most important branches of modern manufacture. Aktual'nye innovacionnye issledovanija: nauka $i$ praktika [Recent innovative research: Science and Practice]. Available from http//www.actualresearch/2011_4/ Article/geo/demidenok20114.htm

6. Levedeva, L.M. (2000) Spravochnik shtukatura [Plasterer's Manual]. 5-e izd., ster. M.: Vysshaja shkola, Izd Centr Akademija. (Rus)

7. Kargin, V.A. (1978) Kolloidnye sistemy i rastvory polimerov: izbrannye tr [Colloidal systems and polymer solutions: Selected papers]. M.: Nauka. (Rus)

8. Klenin, V.I., et al. (1977) Harakteristicheskie funkcii svetorasseivanija dispersnyh sistem [Characteristic features of light scattering of dispersed systems]. Saratov: Izd-vo Saratovskogo un-ta. (Rus)

9. Gelfman, M.I., et al. (2008) Kolloidnaja himija [Colloidal chemistry]. SPb.: Lan'. (Rus)

10. Gomeeva, O.S. (1980) Sbornik zadach $i$ uprazhnenij po fizicheskoj i kolloidnoj himii [Collection of problems and exercises for physical and colloid chemistry]. 3-e izd., pererab. i dop. M.: Vysshaja shk. (Rus)

11. GOST 10277-90 (2001) Shpaklevka. Tehnicheskie uslovija [Putty. Technical conditions]. M.: IPK Izd-vo standartov. (Rus)

12. Udachkin, I.B. \& Aleksandrov, G.G. (1982) Zashhita jacheistyh betonov ot korrozii [Cellular concrete protection against corrosion]. Kiev: Budivel'nik. (Rus) 